\title{
Assessing the Impact of Prognostic Factors on the Survival Time of Cancer Patients: Cox Proportional Hazard Model
}

\section{Sarder A and Kabir R*}

Statistics Discipline, Khulna University, Khulna, Bangladesh

*Corresponding author: Rasel Kabir, Assistant Professor, Statistics Discipline, Khulna University Khulna, Bangladesh, Tel: +8801742251377; Email: raselsh023@yahoo.com

\section{Research Article}

Volume 4 Issue 1

Received Date: December 02, 2019

Published Date: January 29, 2020

DOI: $10.23880 /$ phoa-16000149

\section{Abstract}

Background: Cancer is deathful disease and caused by uncontrolled cell growth. Several prognostic factors are responsible for survival time of cancer patients. The study assesses the impact of influential factors affecting survival time.

Methods: This study consisted of 263 cancer patients who were referred to Khulna Medical College Hospital between May 2016 and November 2017. Survival curve (Kaplan-Meier) is used for comparing the survival function and cox-proportional hazard model is also used for finding the hazard ratio of different prognostic factors.

Results: The prevalence of death due to cancer in this study was found $48.7 \%$. Smoking habit, treatment types, surgery, cancer stage, hopeful and anxiety level are statistically significant at $5 \%$ level of significance. But only betel nut is significant at $10 \%$ level of significance.

Conclusion: A challenge for cancer control is effective communication of risk information for specific cancers like as developing country Bangladesh. The government should take steps to control the prognostic factors associate with cancer for ensuing the health facility.

Keywords: Cancer; Prognostic Factors; Cox Proportional Hazard Model

\section{Introduction}

Cancer is a health burden [1] and deathful disease which is caused by uncontrolled cell growth [2]. It is also called group of diseases and overpass other tissues [3]. According to World Health Organization [4]. Cancer is a generic term for a large group of diseases characterized by the growth of abnormal cells beyond their usual boundaries that can then invade adjoining parts of the body and/or spread to other organs. The American Cancer Society [5] denes cancer as a group of diseases that are characterized by the uncontrolled growth and spread of abnormal cells. It kills more people globally then tuberculosis, HIV and malaria combined [6].

Cancer is often considered a disease of affluence, but about $70 \%$ of cancer deaths occur in low- and middleincome countries [7]. Cancer is a leading cause of death in many wealthy countries, and its toll is rising in poorer regions [8]. The Lancet Oncology predicted that from 20082030, cancer incidence will rise 75 percent globally and will double in the least developed countries [9]. Breast cancer is the world's most common cancer in women [10]. The illness is diagnosed most frequently in developed countries. Based on GLOBOCAN [11] estimates, about 14.1 million new cancer cases and 8.2 million deaths occurred in 2012 worldwide. 
Over the years, the burden has shifted to less developed countries, which currently account for about $57 \%$ of cases and $65 \%$ of cancer deaths worldwide. According to the World Health Organization (WHO), the worldwide incidence of cancer in the year 2002 exceeded 10 million cases, excluding basal and squalors cell cancers of the skin. Globally, the most prevalent types of cancers were breast (5.2 million), colorectal (3.2 million), prostate (3.2 million), lung (1.67 million), stomach (1.6 million), cervical (1.5 million), urinary bladder (1.1 million), liver (0.6 million), and esophageal cancer (0.48 million) in 2008 [8]. By 2030, over 9 million cancer patients are assumed to die in developing countries from different types of cancers [1].

Bangladesh, at 142 million people, is the ninth most populous country in the world [12]. There are 13 to 15 lakh cancer patients in Bangladesh, with about two lakh patients newly diagnosed with cancer each year [13]. The report of World Health Organization (WHO) is also published that the death rate of breast cancer in Bangladesh is high and ranked in 2nd position all over the world. In Bangladesh 3,300 people in urban areas are served by one doctor and more than 15,000 people in rural areas [2]. It creates a burning question about general population health in Bangladesh.

Poor health service in Bangladesh can't touch the dream of modern medical invention. Although new technologies are developing day by day to reduce the number of cancer people. But perspectives to Bangladesh new technologies are not good enough to reduce cancer people. They also believe that an evil spirit is responsible to occurring cancer and punishment for bad deeds. Both illiterate and educated women have insufficient knowledge about breast cancer. This problem is not only for Bangladesh but also other countries [14-16]. So it's needed to increase the doctors and awareness among all population both rural and urban areas in Bangladesh. The awareness can be increased to provide the proper knowledge about factors those are associated with cancer. Like as population health service, socioeconomic status is not good in Bangladesh. This paper presents characteristic of cancer patients and their distribution with respect to survival status as well as compares the survival function of a wide range of prognostic factor. Assess the impact of influential factors affecting survival time. Check out the cox-PH assumption. Therefore, the only outcome considered here is survival [17].

\section{Materials and Methods}

\section{Data Source}

The present study incorporates data from patients who were visited and treated at Radiotherapy and oncology department, Khulna Medical College Hospital, Khulna,
Bangladesh during May 2016 to September 2017 [18,19]. The patients were followed up until November 2017. The patients or patients' family members were contacted to conform their health status (i.e. whether they are still alive or not) and to fill any gaps in their medical records. We had to exclude some patients because of some reasons, first their medical records had incomplete information, second they were related to male and third, their cause of death was not cancer. Eventually a total number of 263 respondents with cancer were included in this analysis $[20,21]$.

\section{Survival Time and Prognostic Factors}

The primary aim was to determine the survivalassociated predictors in cancer. The (complete) survival time was defined as the duration (days/months) from detection to death due to cancer. It is possible that one or more patients experience death due to cause(s) other than cancer or be alive at the end of the study. For these patients, the time from diagnosis to these endpoints were considered as censored survival time. The date of diagnosis and end-point time for each patient was extracted from medical records or contracted by the investigators [22-25].

The 15 explanatory variables divide naturally into four groups: socioeconomic or demographic, clinical factors, clinical and physiological factors. Which includes gender, age, educational status, working environment, residential area, smoking habit, betel nut, chewing tobacco, food habit, treatment history, name treatment, surgery, cancer stage, hopeful, anxiety level? The collected data was approved by Dr. Mukitul Huda, Radiotherapy and oncology department, Khulna Medical College and Hospital, Khulna, Bangladesh [26-28].

\section{Preparing the Data}

"Foreign" package 23 was used to convert the data, which stored in IBM SPSS statistics 20 (Chicago, IL, USA) to $\mathrm{R} \times 64$ 3.5.1, open source statistical software. When it was necessary, patients were stratified upon age group at diagnosis $(<20$, $20-44,45-64,65-89$, and $89<$ in years, recoded the name of treatment as homeopathy and operation if the patient has taken homeopathy, chemotherapy, radiotherapy and any type of surgery for treating cancer, if the patients has taken treatment from local area and someone who is not doctor by consciously or unconsciously is considered as kobiraji and village treatment. combined satge I and II and stage III and IV for significance analysis. Others variables are remain same as questionnaire [29].

\section{Statistical Methods}

In clinical studies, individual data is usually available on 
time to death or time to last seen alive. The K-M estimator for the survival curves is usually used to analyze individual data. Kaplan Meier plots were used for graphical depictions of patient experience. The logrank test is used to test the null hypothesis that there is no difference between the populations in the probability of an event (here a death) at any time point [30]. Alternatively log rank test is used to test whether two (or more) survival functions are equal. It involves obtaining the expected number of deaths in (say) the treatment group at time ti if the hazard functions for the two groups were equal. A semi parametric model is a statistical model that has parametric and nonparametric components. The non-parametric method does not control for covariates and it requires categorical predictors. When we have several prognostic variables, we must use multivariate approaches. But we cannot use multiple linear regression or logistic regression because they cannot deal with censored observations. We need another method to model survival data with the presence of censoring. One very popular model in survival data is the Cox proportional hazards model, which is proposed by Cox [31].

\section{Results}

\section{Patient's Characteristics}

In the study there were more female than male cancer patients. Among 263 patients there were 108 male and 155 female. That is among all the respondents $41.1 \%$ were male and $58.9 \%$ were female. Female were largely affected by cancer in this study. A large portion (39.5\%) of our patients is fallen in the age 45-64 years and they have little risk to death. Oppositely, only $6.1 \%$ patients are fallen in above 89 years age. We recoded a respondent have any class of education fallen in literate group and have not any class of education fallen in illiterate group. About $27.8 \%$ of respondents had no class of education but $72.2 \%$ respondents were educated. So it has been clear that, most of the respondents of this study had any class of education. Since this study was conducted in a residential city corporation of Bangladesh and most of the respondents of this study came for their treatments from the urban and nearest rural area and it were simple to have more literate individuals in our selected sample (Table 1).

\begin{tabular}{|c|c|c|c|}
\hline \multicolumn{4}{|c|}{ Survival Status } \\
\hline Variables & Alive N(\%) & Death N(\%) & Total N(\%) \\
\hline \multicolumn{4}{|c|}{ Demographic factors } \\
\hline \multicolumn{4}{|c|}{ Gender } \\
\hline Male & $43(39.8)$ & $65(60.2)$ & 108(41.1) \\
\hline Female & $92(69.4)$ & $63(40.6)$ & $155(58.9)$ \\
\hline \multicolumn{4}{|c|}{ Age(Year) } \\
\hline$<20$ & $7(46.7)$ & $8(53.3)$ & $15(5.7)$ \\
\hline $20-44$ & $26(63.4)$ & $15(36.6)$ & $41(15.6)$ \\
\hline $45-64$ & $60(57.7)$ & $44(42.3)$ & $104(39.5)$ \\
\hline $65-89$ & $37(42.5)$ & $50(57.5)$ & $87(33.1)$ \\
\hline $89<$ & $5(31.2)$ & $11(68.8)$ & $16(6.1)$ \\
\hline \multicolumn{4}{|c|}{ Educational status } \\
\hline Illiterate & $31(42.5)$ & $42(57.5)$ & $73(27.8)$ \\
\hline Literate & $104(54.7)$ & $46(45.3)$ & $190(72.2)$ \\
\hline \multicolumn{4}{|c|}{ Working environment } \\
\hline Hygienic & $98(51.6)$ & $92(48.4)$ & $190(72.2)$ \\
\hline Unhygienic & $37(50.7)$ & $36(49.3)$ & $73(27.8)$ \\
\hline \multicolumn{4}{|c|}{ Residential area } \\
\hline Rural & $89(49.4)$ & $91(50.6)$ & $83(31.6)$ \\
\hline Urban & $46(55.4)$ & $37(44.6)$ & $180(68.4)$ \\
\hline \multicolumn{4}{|c|}{ Habitual factors } \\
\hline \multicolumn{4}{|c|}{ Smoking Habit } \\
\hline Non-smoker & $114(59.1)$ & $79(40.9)$ & 193(73.4) \\
\hline
\end{tabular}




\begin{tabular}{|c|c|c|c|}
\hline Smoker & $21(30)$ & $49(70)$ & $70(26.6)$ \\
\hline \multicolumn{4}{|c|}{ Betel nut } \\
\hline No & $81(61.4)$ & $51(38.6)$ & $132(50.2)$ \\
\hline Yes & $54(41.2)$ & $77(58.8)$ & $70(49.8)$ \\
\hline \multicolumn{4}{|c|}{ Chewing Tobacco } \\
\hline Yes & $32(34.8)$ & $60(65.2)$ & $92(35.0)$ \\
\hline No & $103(60.2)$ & $68(39.8)$ & $171(65.0)$ \\
\hline \multicolumn{4}{|c|}{ Food habit } \\
\hline Vegetarian & $29(58)$ & $21(42)$ & $50(19.0)$ \\
\hline Standard & $68(51.5)$ & $64(48.5)$ & $132(50.2)$ \\
\hline Rich & $17(58.6)$ & $12(41.4)$ & $29(11.0)$ \\
\hline Lower & $21(40.4)$ & $31(59.6)$ & $52(19.8)$ \\
\hline \multicolumn{4}{|c|}{ Clinical factors } \\
\hline \multicolumn{4}{|c|}{ Treatment history } \\
\hline No & $56(54.9)$ & $46(45.1)$ & $102(38.8)$ \\
\hline Yes & $79(49.1)$ & $82(50.9)$ & $161(61.2)$ \\
\hline \multicolumn{4}{|c|}{ Name treatment } \\
\hline No treatment & $56(54.9)$ & $46(45.1)$ & $102(38.9)$ \\
\hline Homeopathy and operation Kobiraji & $73(56.2)$ & $57(43.8)$ & $130(49.6)$ \\
\hline Village treatment & $5(16.7)$ & $25(83.3)$ & $30(11.5)$ \\
\hline \multicolumn{4}{|c|}{ Surgery } \\
\hline No & $55(41.4)$ & $78(58.6)$ & $133(50.6)$ \\
\hline Yes & $80(61.5)$ & $50(38.5)$ & $130(49.4)$ \\
\hline \multicolumn{4}{|c|}{ Cancer stage } \\
\hline Satge- 1 and 2 & $66(74.2)$ & $23(25.8)$ & $89(33.8)$ \\
\hline Satge- 3 and 4 & $69(39.7)$ & $105(60.3)$ & $174(66.2)$ \\
\hline \multicolumn{4}{|c|}{ Psychological factors } \\
\hline \multicolumn{4}{|c|}{ Hopeful } \\
\hline Yes & $111(63.4)$ & $64(36.6)$ & $175(66.5)$ \\
\hline No & $24(27.3)$ & $64(72.7)$ & $88(33.5)$ \\
\hline \multicolumn{4}{|c|}{ Anxiety level } \\
\hline Low & $41(77.4)$ & $12(22.6)$ & $53(20.2)$ \\
\hline Medium & $63(56.2)$ & $49(43.8)$ & $112(42.6)$ \\
\hline High & $31(31.6)$ & $67(68.4)$ & $98(37.3)$ \\
\hline
\end{tabular}

Table 1: Percentage Distribution for Different Factors.

We had only two categories for working environment which are hygienic and unhygienic. Since most of the respondents in this study were female and their occupation was housewife, the working environment of them was hygienic for health. But the respondents who were related to farming occupation, most of them had unhygienic environment around them. About 72.2\% respondents belonged to hygienic environment and $27.8 \%$ respondent's belonged to unhygienic environment. In our study there were more urban people than rural patients. About 31.6\%( 83 patients) were from urban area and $68.4 \%$ (180 patients) rural area [32-35].

Most of the respondents hadn't the habit of smoking. 
Here the proportion of female respondents were relatively large than male and in our country most of the female population haven't the habit of smoking. So the proportion of smoker is relatively smaller than the proportion of nonsmoker. About 73.4\% respondents hadn't the smoking habit and $26.6 \%$ respondents were badly addicted to smoke among 263 respondents. About 49.8\% respondents had a habit of eating betel nut. On the other hand, $50.2 \%$ hadn't any habit of eating betel nut out of 263 patients [36-38]. That means there were a small proportion of respondents having the habit of eating betel nut. Of 263 patients 19\% (50 respondents) are vegetarian, $50.2 \%$ (132 respondents) consume standard food, 11\% (29 respondents) consume rich food and 19.8\% (52 respondents) consume lower class food. Most of the patients had a habit of eating standard food which is essential for good health. Previous history of treatment was taken for investigating whether the respondents took other treatment like homeopathy, tumor operation, chemotherapy and radiotherapy; kobiraji and village doctor treatment and these had any impact on their survival time. Most of the respondents 130 (49.6\%) has taken homeopathy treatment as well as operation. The numbers of respondents having surgery in the past were $49.4 \%$ and the respondents who hadn't any surgery were 50.6\%. Most of the respondents are fallen in stage-3 and stage-4(66.2\%). So they have little chance to rescue from death. $175(66.5 \%)$ patients are hopeful about rescue from death oppositely only $88(33.5 \%)$ patients have no hopeful. About $112(42.6 \%)$ patients are medium anxious about their diseases [39-41].

\section{Kaplan-Meier Survival Analysis and Log Rank Test (Figures 1-10)}
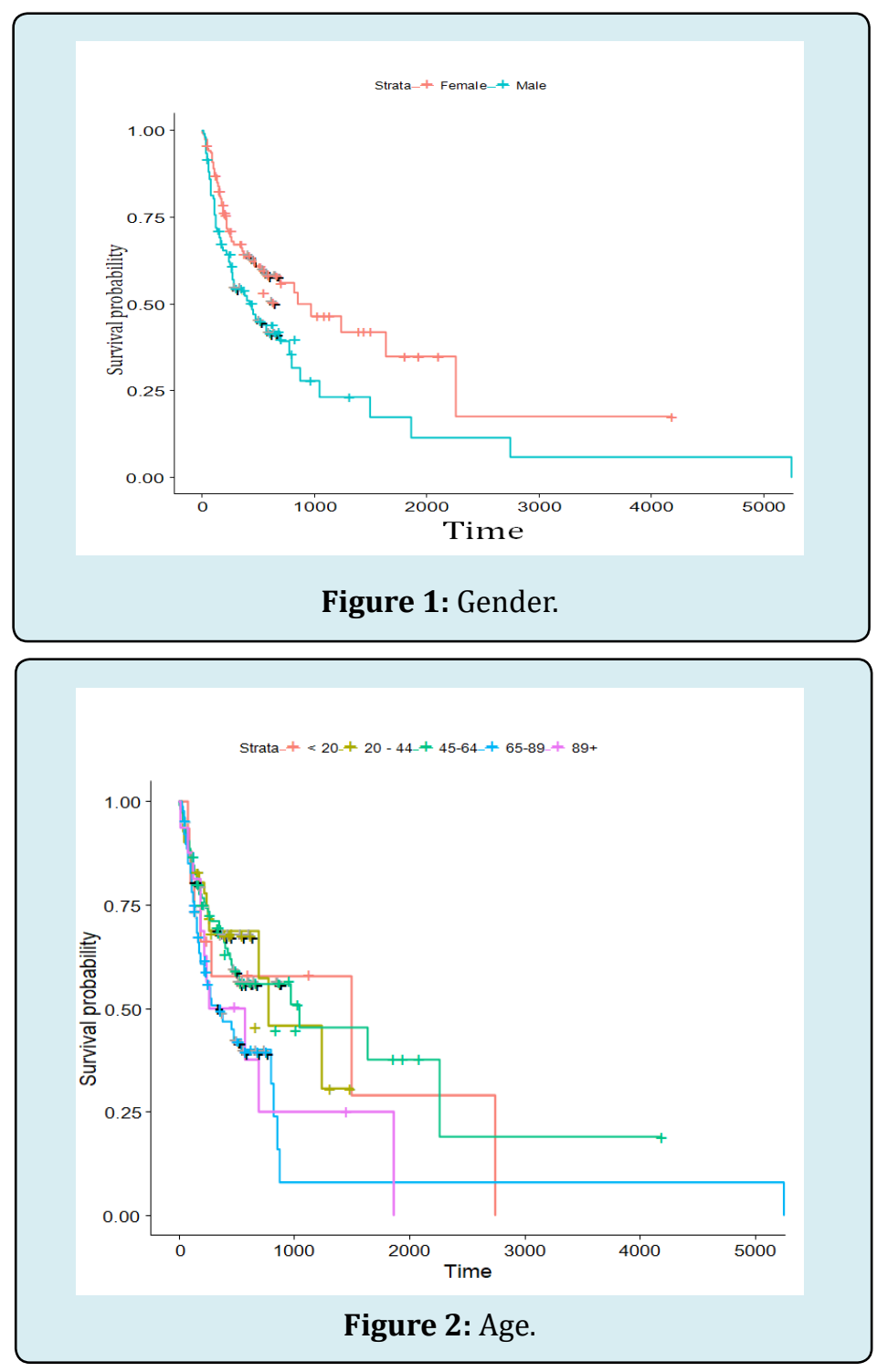

Sarder A and Kabir R. Assessing the Impact of Prognostic Factors on the Survival Time of Cancer Patients: Cox Proportional Hazard Model. Public H Open Acc 2020, 4(1): 000149. 


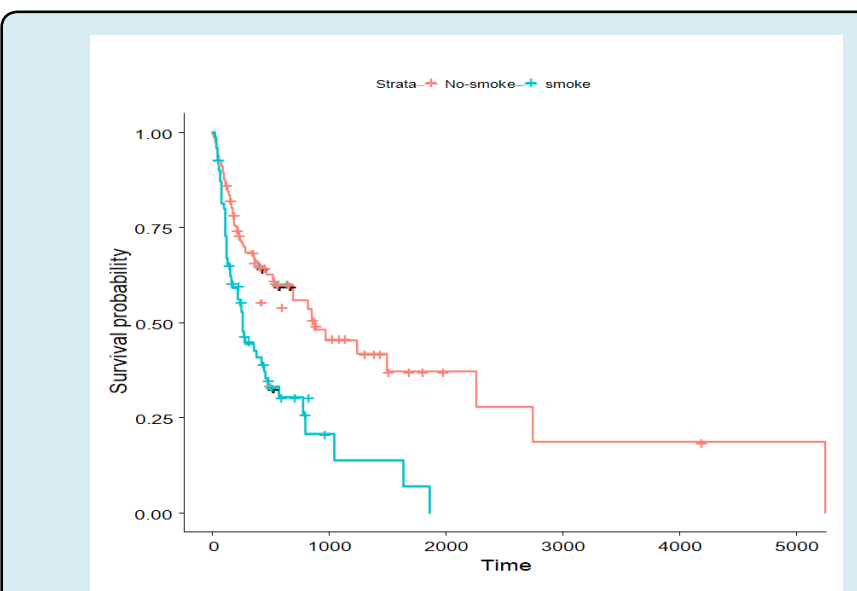

Figure 3: Smoking habit.
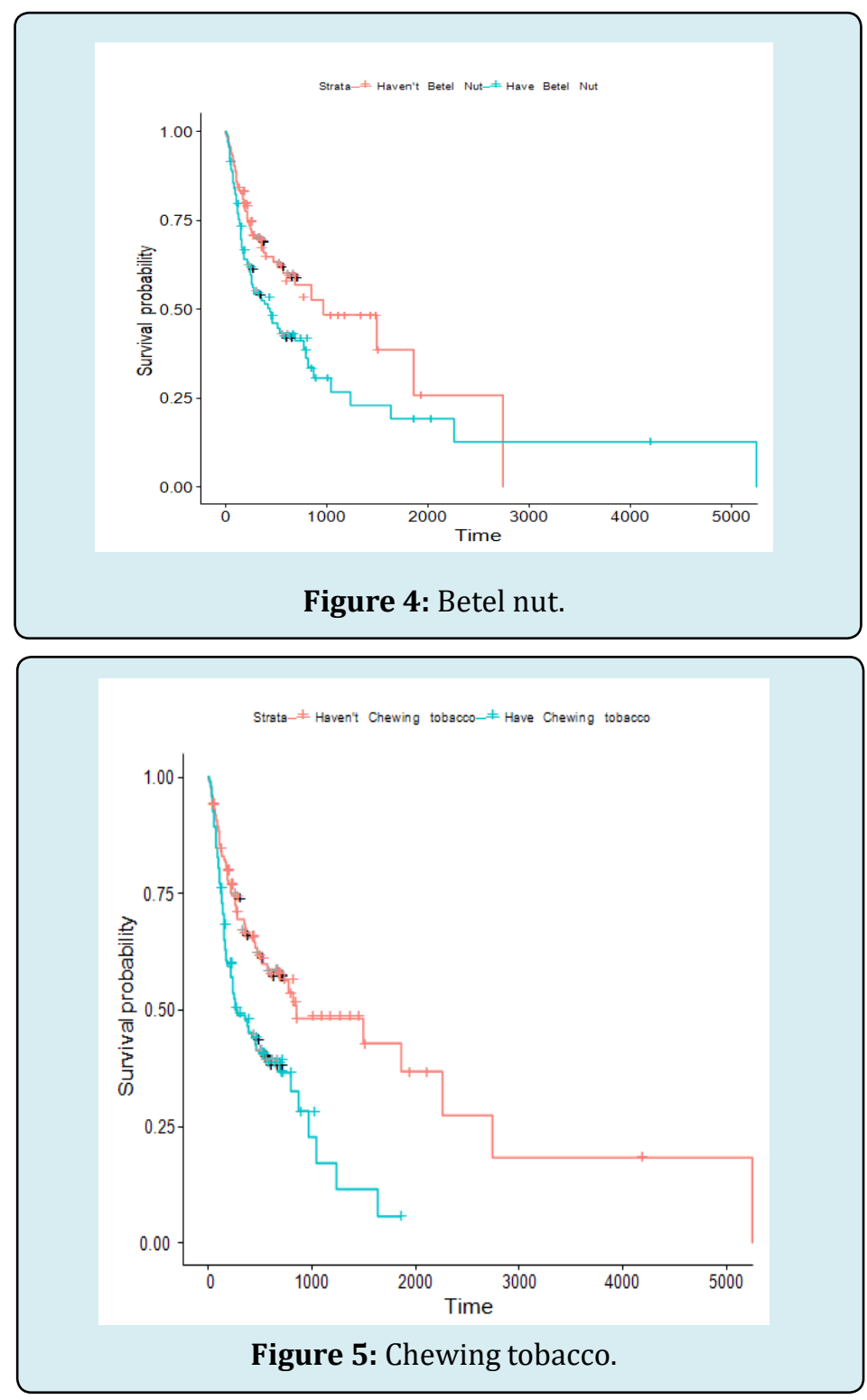

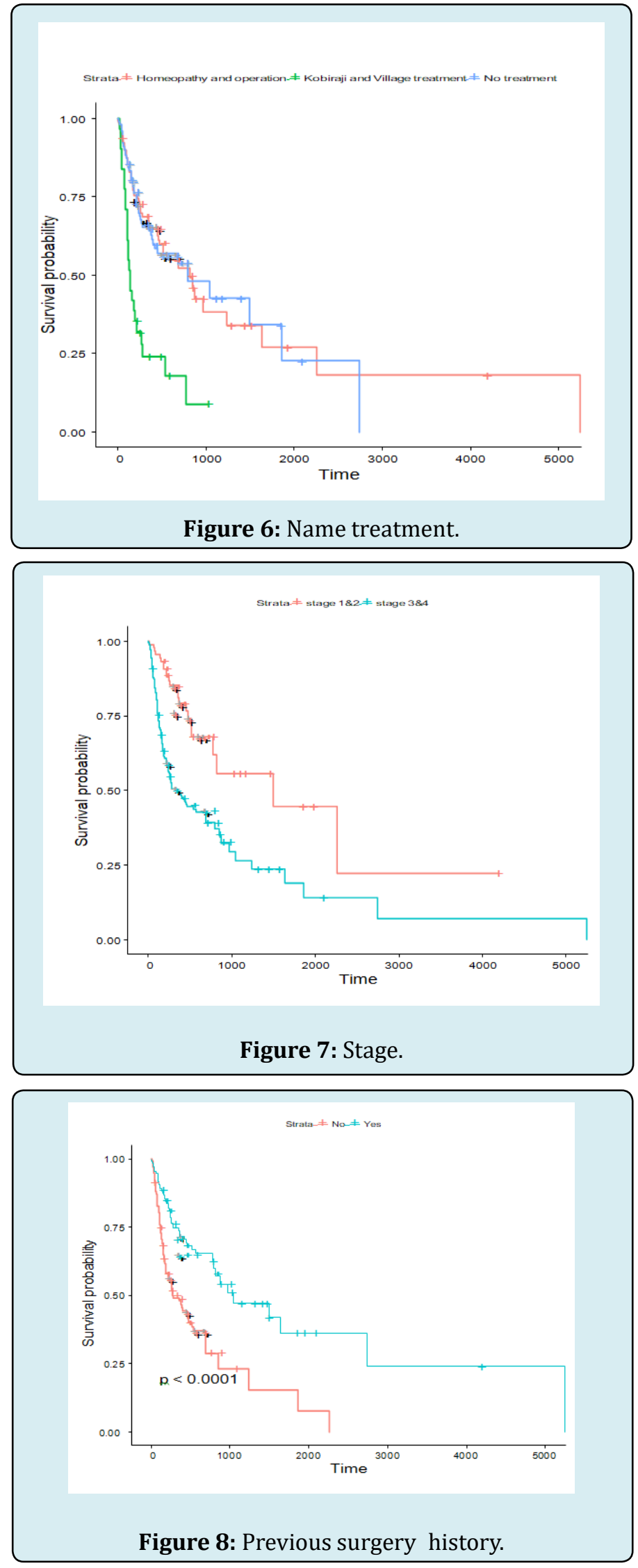

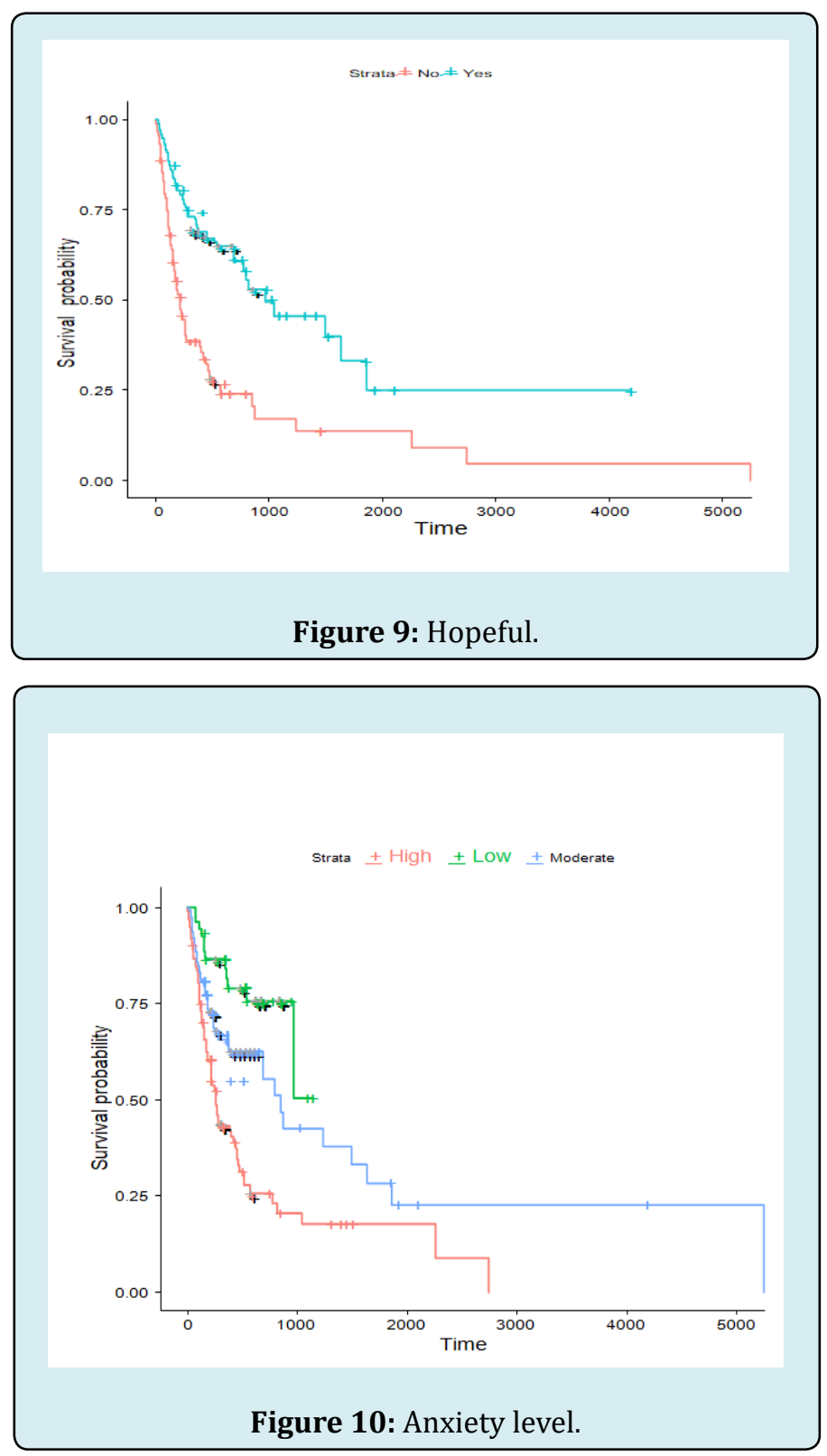

Figures 1-10: Kaplan meier survival curves.

The Kaplan-Meier survival probability shown in Figures 1-10 against survival time and Table 2 shows survival time in term of mean survival time and median survival time as well as p-value of log rank test result. The survival curve survival curve for female, non-smoker, haven't betel nut, haven't tobacco chewing, homeopathy and operation, kobiraji and village treatment, stage- 1 and stage-2, have previous treatment, hopeful about rescue from death and lower as well as moderate category are higher which indicates that those categories have higher probability to survive compared to remains at different time points. Female and male are two categories for gender. From the figure we also see that the survival curve (1) for female is higher than male at time points so they are less likely to survive compared to female patients which indicates that female respondent was survived more than male respondent between detection of cancer and death time. Whereas a female respondent was survived 1477 days with median 964 days from diagnosis to death time [42]. 
Public Health Open Access

\begin{tabular}{|c|c|c|c|c|c|}
\hline \multirow[t]{3}{*}{ Variables } & \multirow{3}{*}{$\begin{array}{c}\text { Survival } \\
\text { Mean } \\
\text { Survival time }\end{array}$} & \multirow{3}{*}{$\begin{array}{c}\text { time } \\
\text { Median Survival time }\end{array}$} & \multirow{3}{*}{$\begin{array}{c}\text { Log } \\
\text { Chi-square Value }\end{array}$} & \multicolumn{2}{|c|}{ rank test } \\
\hline & & & & \multirow{2}{*}{$\mathrm{DF}$} & \multirow{2}{*}{ P-value } \\
\hline & & & & & \\
\hline \multicolumn{6}{|c|}{ Demographic factors } \\
\hline Gender & & & 7.529 & 1 & 0.006 \\
\hline Male & 930.882 & 415 & & & \\
\hline Female & 1476.985 & 964 & & & \\
\hline Age(Year) & & & 10.316 & 4 & 0.035 \\
\hline$<20$ & 1287.048 & 1944 & & & \\
\hline $20-44$ & 858.669 & 772 & & & \\
\hline $45-64$ & 1542.178 & 1041 & & & \\
\hline $65-89$ & 798.777 & 357 & & & \\
\hline $89<$ & 704.188 & 261 & & & \\
\hline Educational status & & & 2.381 & 1 & 0.123 \\
\hline Illiterate & 769.083 & 515 & & & \\
\hline Literate & 1642.548 & 689 & & & \\
\hline Working environment & & & 0.127 & 1 & 0.721 \\
\hline Hygienic & 1132.376 & 685 & & & \\
\hline Unhygienic & 1411.439 & 772 & & & \\
\hline Residential area & & & 2.322 & 1 & 0.128 \\
\hline Rural & 1396.36 & 874 & & & \\
\hline Urban & 1228.333 & 515 & & & \\
\hline \multicolumn{6}{|c|}{ Habitual factors } \\
\hline Smoking Habit & & & 20.115 & 1 & $<0.001$ \\
\hline Non-smoker & 1752.175 & 872 & & & \\
\hline Smoker & 528.136 & 261 & & & \\
\hline Betel nut & & & 7.27 & 1 & 0.007 \\
\hline No & 1275.104 & 964 & & & \\
\hline Yes & 1169.45 & 446 & & & \\
\hline Chewing Tobacco & & & 14.477 & 1 & 0.001 \\
\hline Yes & 577.966 & 285 & & & \\
\hline No & 1782.907 & 847 & & & \\
\hline Food habit & & & 4.017 & 3 & 0.26 \\
\hline Vegetarian & 919.554 & 521 & & & \\
\hline Standard & 940.089 & 819 & & & \\
\hline Rich & 2017.32 & 569 & & & \\
\hline Lower & 1092.901 & 394 & & & \\
\hline \multicolumn{6}{|c|}{ Clinical factors } \\
\hline Treatment history & & & 0.836 & 1 & 0.353 \\
\hline No & 931.279 & 537 & & & \\
\hline Yes & 1589.708 & 819 & & & \\
\hline
\end{tabular}




\begin{tabular}{|c|c|c|c|c|c|}
\hline Name treatment & & & 28.852 & 2 & $<0.001$ \\
\hline No treatment & 1173.61 & 799 & & & \\
\hline Homeopathy and operation & 1565.917 & 819 & & & \\
\hline Kobiraji and Village & 286.273 & 137 & & & \\
\hline \multicolumn{6}{|c|}{ Treatment } \\
\hline Surgery & & & 24.68 & 1 & $<0.001$ \\
\hline No & 635.71 & 276 & & & \\
\hline Yes & 2003.91 & 1041 & & & \\
\hline \multicolumn{6}{|c|}{ Psychological factors } \\
\hline Hopeful & & & 34.491 & 1 & $<0.001$ \\
\hline Yes & $1628 \ldots 675$ & 964 & & & \\
\hline No & 715.505 & 214 & & & \\
\hline Anxiety level & & & 30.687 & 2 & $<0.001$ \\
\hline Low & 878.708 & 874 & & & \\
\hline Medium & 1715.725 & 261 & & & \\
\hline High & 674.318 & 689 & & & \\
\hline
\end{tabular}

Table 2: Compare the survival time of different groups and log rank test.

Here, the p-value (.006) is less than .05 conclude that there is significant evidence of a difference in survival times for male and female patients. Above 89 years older patients have lowest mean survival time (704.188 days) and median survival time (261.000 days). $P$ value indicates a significant different between different categories for age variable at a distinct time point. Hence the survival curves (2) reflect this. Similarly, non-smoker patients have higher survival probability with mean and median survival time is 1752 days and 872 days. Significant $p$ value $(<0.001)$ supported a significance difference between non-smoker and smoker. So smoking habits seriously reduce the survival probability (3) and increase the risk of committing to death. As same as smoking habit the survival curve $(4,5)$ is higher for non-betel nut and chewing tobacco user patient as well as the mean and median is also large for non-betel nut (1275 days) and tobacco users (1783). Both have significant p-value indicates the significant differences for survival curves.

Homeopathy and operation increase the mean (1566 days) and median (819 days) survival time and have a higher survival curve (6) which indicates that at different time point the probability is lower but the survival probability is highly affected by kobiraji and village treatment which holds the mean and median survival time only 286 days and 137 days respectively with $\mathrm{p}$-value $<0.001$. It is considered that Stage- 3 and Stage- 4 is more dangerous stages for cancer diseases and patient survive relatively less time in this group and early meet to death. Also our result supported this prediction. Stage- 3 and Stage- 4 have lower survival curves with 1004 days mean survival time and 343 days median survival time. Survival curves (7) are not equal because $p$-value is significant $(<0.001)$. Surgery patients has higher mean (2004 days) and median (1041 days) survival time compared to who haven't any treatment. Similarly the survival probability is high and p-value $(<.001)$ indicates the unequal survival curve (8). Hopeful patients have large mean (1629 days) and median (964 days) survival time oppositely hopeless patient's mean (716 days) and median (214) is quite low. So no doubt that survival curve (9) is high for hopeful patients. Medium and lower anxiety for rescuing from cancer increase the mean and median survival time and the survival curves $(10)$ are not equal $(\mathrm{p}<0.001)$.

\section{Cox Proportional Hazard Model}

In this study, Cox Proportional Hazard Model is fitted for the data. Variables are identified as significant using at 0.05 significance level in the model. Here the maximum likelihood estimates with the Corresponding coefficient, hazard ratio, confidence interval and p-value for different covariate groups are given below (Table 3). It is observed from the Table that smoking habit, name treatment surgery, cancer stage, hopeful and anxiety level are statistically significant at $5 \%$ level of significance. But only betel nut is significant at $10 \%$ level of significance. 


\begin{tabular}{|c|c|c|c|c|}
\hline Variables & Coefficient & $H R$ & CI & P-value \\
\hline \multicolumn{5}{|c|}{ Demographic factors } \\
\hline \multicolumn{5}{|c|}{ Gender } \\
\hline Male & \multirow{3}{*}{0.12} & \multirow{3}{*}{1.128} & \multirow{3}{*}{$0.642-1.981$} & \multirow{2}{*}{0.676} \\
\hline Female* & & & & \\
\hline Age(Year) 20-44 & & & & \multirow{5}{*}{$\begin{array}{l}0.964 \\
0.702 \\
0.496 \\
0.634 \\
0.697\end{array}$} \\
\hline $45-64$ & \multirow{4}{*}{$\begin{array}{l}-0.206 \\
-0.324 \\
-0.227 \\
-0.214\end{array}$} & 0.814 & \multirow{4}{*}{$\begin{array}{c}0.284-2.336 \\
0.285-1.838 \\
0.312-2.032 \\
0.275-2.368\end{array}$} & \\
\hline $65-89$ & & 0.724 & & \\
\hline $89<$ & & 0.797 & & \\
\hline$<20^{*}$ & & 0.807 & & \\
\hline \multicolumn{5}{|c|}{ Educational status } \\
\hline Illiterate & \multirow{2}{*}{-0.007} & \multirow{2}{*}{0.993} & \multirow{2}{*}{$0.636-1.552$} & \multirow{2}{*}{0.977} \\
\hline Literate* & & & & \\
\hline \multicolumn{5}{|c|}{ Working environment } \\
\hline Hygienic & \multirow{2}{*}{0.243} & \multirow{2}{*}{1.276} & \multirow{2}{*}{$0.781-2.083$} & \multirow{2}{*}{0.33} \\
\hline Unhygienic* & & & & \\
\hline \multicolumn{5}{|c|}{ Residential area } \\
\hline $\begin{array}{l}\text { Urban } \\
\text { Rural* }\end{array}$ & 0.182 & 1.2 & $0.795-1.811$ & 0.386 \\
\hline \multicolumn{5}{|c|}{ Habitual factors } \\
\hline \multicolumn{5}{|c|}{ Smoking Habit } \\
\hline Smoker & \multirow{2}{*}{0.658} & 1021 & 10002420 & 0025 \\
\hline Non-smoker* & & 1.931 & $1.088-3.429$ & $0.0<5$ \\
\hline & Betel nut & & & \\
\hline Yes & 0055 & 1057 & $0662-1686$ & 00817 \\
\hline No* & 0.055 & $1.05 /$ & $0.66<-1.686$ & $0.081 /$ \\
\hline & hewing Toba & & & \\
\hline Yes & & & & \\
\hline No * & 0.22 & 1.247 & $0.767-2.026$ & 0.374 \\
\hline & Food Habi & & & \\
\hline Standard & & & & 0.249 \\
\hline Rich & 0.227 & 1.255 & $0.738-2.135$ & 0.401 \\
\hline Lower & -0.487 & 0.615 & $0.278-1.361$ & 0.23 \\
\hline Vegetarian* & 0.186 & 1.205 & $0.653-2.220$ & 0.551 \\
\hline & Clinical fact & & & \\
\hline & reatment his & & & \\
\hline No & 052 & 1602 & 07022621 & 0102 \\
\hline Yes* & 0.32 & 1.083 & $0.102-3.021$ & 0.103 \\
\hline & Name treatm & & & \\
\hline Homeopathy and operation & 1.327 & 3.77 & $1.951-7.285$ & 0 \\
\hline
\end{tabular}




\begin{tabular}{|c|c|c|c|c|}
\hline Kobiraji and Village treatment & 0.719 & 2.053 & $0.867-4.864$ & 0.102 \\
\hline No treatment* & & & & \\
\hline \multicolumn{5}{|c|}{ Surgery } \\
\hline No & \multirow{2}{*}{0.592} & \multirow{2}{*}{1.808} & \multirow{2}{*}{$1.215-2.691$} & \multirow{2}{*}{0.004} \\
\hline Yes* & & & & \\
\hline \multicolumn{5}{|c|}{ Cancer stage } \\
\hline Stage- 3 and 4 & \multirow{2}{*}{0.801} & \multirow{2}{*}{2.228} & \multirow{2}{*}{$1.378-3.603$} & \multirow{2}{*}{0.001} \\
\hline Stage- 1 and $2 *$ & & & & \\
\hline \multicolumn{5}{|c|}{ Psychological factors } \\
\hline \multicolumn{5}{|c|}{ Hopeful } \\
\hline No & \multirow{2}{*}{0.659} & \multirow{2}{*}{1.933} & \multirow{2}{*}{$1.226-3.047$} & \multirow{2}{*}{0.005} \\
\hline Yes* & & & & \\
\hline \multicolumn{5}{|c|}{ Anxiety level Low } \\
\hline Low & -0.894 & 0.409 & 0.201-0.834 & 0.014 \\
\hline High & -0.16 & 0.852 & $0.548-1.324$ & 0.477 \\
\hline Medium* & & & & \\
\hline
\end{tabular}

Table 3: Result of Cox proportional hazard model.

At $5 \%$ level of significance the hazard ratio of male gender have 1.128 times more risk of dying compare with female patients. So the patients who are male have 1.128 times more risk of dying compare to the patients who are female. Smoker patients have 1.931 times more risk of dying than non-smoker. The patients who have the habit of eating betel nut have 1.057 times more risk of dying to compare with the patients who haven't the habit betel nut. The patients having kobiraji and village treatment have 2.053 times more risk but the patients having before homeopathy and operation types treatment have 3.770 times more risk of committing to death compare with no treatment taker patient before this treatment. Hazard rate is higher for nonsurgery patients. The patients at stage- 3 and stage- 4 have 2.228 times more hazard of dying reflects that the patients who are in stage- 3 and stage- 4 have more chance to early meet to death. Hopeless patients have 1.933 times more risk. On the country lower and higher anxious patients have low risk of dying compared with medium anxious patients.

At $1 \%$ level of significance the result suggested that cox proportional hazard is significance for gender, smoking habit betel nut, chewing tobacco, name treatment, surgery cancer stage, and hopeful and anxiety level. Whereas only age is significance at $5 \%$ level of significance but educational status, residential area are significant at $10 \%$ level of significance. All significant variables reflect that hazard is constant over time or hazard is proportionally constant at different time points [43].

\section{Discussion}

Our study showed that $48.7 \%$ patients died till last follow-up time. So the survival probability is 0.51 for a cancer patient. Based on the results of log rank test gender, smoking habit, betel nut, chewing tobacco, name treatment, surgery, cancer stage, hopeful and anxiety level are statistically significance. So those variables are difference in survival times for cancer patients [44]. But age, educational status, working environment, residential area and treatment history are not statistically insignificance. So those variables are no difference in survival times for cancer patients. Ibnu Sina UMI Hospital conducted a retrospective cohort study of breast cancer cases in 2013-2016 was selected 108 cases out of 436 all patient. They found the survival probability was 0.029 [45] also found that age was statistically significance with $\log$ rank value $7.763(\mathrm{df}=2)$ as well as $\mathrm{p}<0.05$.

According to the results of our analysis male patients have more risk of dying. But the patients 45-64 and 65-89 years have lower risk compare to the age below 20 years. Similarly hygienic, urban, tobacco chewing user, standard, lower, have treatment history, homeopathy and operation, kobiraji and village treatment, have surgery, stage-3 and stage- 4 and hopeless patients have higher hazard of committing to death. In a retrospective study of determining factors for mortality during treatment among tuberculosis patients we found that hazard is higher (1.6 times) for male patients with $\mathrm{p}$ value 0.006 . But the hazard ratio for urban and rural is unity. On the other hand $35-54$ and above 55 years patients have higher risk 1.4 and 3.8 times more than 


\section{Public Health Open Access}

below 15 years and 15-34 years patients [46].

A study conducted in Ethiopia, women had 1.08 times more risk than male patients during anti TB treatment [16]. So in Bangladesh, we get opposite of this results. In British Columbia, a study was conducted on breast cancer 15830 women diagnosed. They were divided into eight groups according to patients' ages and stage of disease Either Cox's $\mathrm{PH}$ model or stratified Cox model was fitted to each group according to the PH assumption and tested using Schoenfeld residuals.

The data show that in the group of patients under age 50 years old and over age 50 with stage I cancer, the highest hazard was related to radiotherapy (HR= 3.15, CI: 1.85-5.35) and chemotherapy (HR=3, CI: 2.29-3.93) respectively. For both groups of patients with stage II cancer, the highest risk was related to radiotherapy ( $\mathrm{HR}=3.02, \mathrm{CI}$ : 2.26-4.03) (HR=2.16, CI:1.85-2.52). For both groups of patients with stage III cancer, the highest risk was for surgery ( $\mathrm{HR}=0.49$, CI: 0.33-0.73), ( $\mathrm{HR}=0.45$, CI: 0.36-0.57). For patients of age 50 years or less with stage IV cancer, none of the treatments were statistically significant. In group of patients over age 50 years old with stage IV cancer, the highest hazard was related to surgery (HR=0.64, CI: 0.53-0.78). Cox ph assumptions supported for gender, age, smoking habit, betel nut, chain tobacco, name treatment, surgery, cancer stage, hopeful and anxiety at 5\% level of significance. So their survival curves are independent of time. Therefore their survival probability is proportional or constant over time. Here we use Kaplan Meier survival's p-value instead of Schoenfeld residual analysis.

\section{References}

1. Rafia P, Shaikh SR, Syeda AS, Zakir HH (2015) Cancer Types and Treatment Modalities in Patients Attending at Delta Medical College Hospital. Delta Medical College Journal 3(2): 57-62.

2. Ahmed K, Asaduzzaman S, Bashar MI, Hossain G, Bhuiyan $\mathrm{T}$ (2015) Association Assessment among Risk Factors and Breast Cancer in a low Income Country: Bangladesh. Asian Pac J Cancer Prev 16(17): 7507-7512.

3. Baghestani AR, Moghaddam SS, Majd H, Akbari M, Nassi $N$ (2015) Survival analysis of patients with breast cancer using weibull Parametric Model. Asian Pac J Cancer Prev 16(18): 8567-8571.

4. (2002) World Health Organization. National cancer control programmes: policies and managerial guidelines. World Health Organization.

5. (2008) American Cancer Society. Cancer facts \& gures.
The Society.

6. Gaurisankar SA, Tanya D (2008) Anti-cancer eects of curcumin: cycle of life and death. Cell division 3(1): 1-14.

7. Peggy P (2008) “Westernizing” Women's Risks? Breast Cancer in Lower-Income Countries. New England Journal of Medicine 358: 213-216.

8. Jemal A, Bray F, Center MM, Ferlay J, Ward E, et al. (2011) Global cancer statistics. CA a cancer journal for clinicians 61(2): 69-90.

9. Freddie B, Ahmedin J, Nathan G, Jacques F, David F (2012) Global cancer transitions according to the human development index (2008-2030): A population-based study. The lancet oncology 13(8): 790-801.

10. Jacques F, Hai RS, Freddie B, David F, Colin M, et al. (2010) Estimates of worldwide burden of cancer in 2008: Globocan 2008. International journal of cancer 127(12): 2893-2917.

11. Ferlay J, Soerjomataram I, Ervik M, Dikshit R, Eser S, et al. (2012) Globocan 2012: Estimated Cancer Incidence, Mortality and Prevalence Worldwide in 2012. International Agency for Research on Cancer.

12. Israt R, Sekander HK (2006) Factors Causing Malnutrition among under Five Children in Bangladesh. Pak J Nutr 5(6): 558-562.

13. Syed AH, Richard S (2013) Cancer Control in Bangladesh. Japanese journal of clinical oncology 43(12): 1159-1169.

14. Morse EP, Maegga B, Joseph G, Miesfeldt S (2014) Breast Cancer Knowledge, Beliefs, and Screening Practices among Women Seeking Care at District Hospitals in Dar Es Salaam, Tanzania. Breast Cancer: basic and clinical research 8: 73-79.

15. Altay B, Avci IA, Rizalar S, Oz H, Meral D (2015) Breast and cervical cancer knowledge and awareness among university students. Asian Pac J Cancer Prev 16(5): 1719-1724.

16. Mary CW, Dawn MH, Jennifer EB, Lucy AP, Melissa G, et al. (2014) Age and cancer risk. American journal of preventive medicine 46(3): S7-S15.

17. Ozkaraman A, Culha I, Fadiloglu ZC, Kosgeroglu N, Gokce S, et al. (2015) Relationships between social support and social image concerns in Turkish women with breast cancer. Asian Pac J Cancer Prev, 16(5): 1795-1802.

18. Kellie B, Karen B, John B (2014) Association between Latitude and Breast Cancer Incidence in Mainland 
Australian Women. Journal of Cancer Research 2014: $1-9$.

19. Chapman JW, Ocallaghan CJ, Hu N, Ding K, GA Y, et al. (2013) Innovative Estimation of Survival Using LogNormal Survival Modelling on ACCENT database. British journal of cancer 108(4): 784-790.

20. Liu MX, Li J, Geng YL, Wang YC, Li J, et al. (2014) Correlation study of knowledge and behavior regarding breast care among female undergraduate students in China. Asian Pacic Journal of Cancer Prevention 15(24): 10943-10947.

21. Qichang C, Ping G, He H (2010) Analyzing concurrent programs title for potential programming errors. Modern Software Engineering Concepts and Practices, pp: 380 .

22. David R Cox (1972) Regression models and life-tables (with discussion). Journal of the Royal Statistical Society 34: 187-220.

23. Gathani T, Ali R, Balkwill A, Green J, Reeves G, at al. (2014) Ethnic differences in breast cancer incidence in England are due to differences in known risk factors for the disease: prospective study. British journal of cancer 110(1): 224-229.

24. Kenneth RH (1995) Graphical methods for assessing violations of the proportional hazards assumption in cox regression. Statistics in medicine 14(15): 1707-1723.

25. Katharina H, Andreas W (2012) Software for semiparametric shared gamma and log- normal frailty models: An overview. Computer methods and programs in biomedicine 107(3): 582-597.

26. Joanna Kruk (2014) Overweight, obesity, oxidative stress and the risk of breast cancer. Asian Pac J Cancer Prev 15(22): 9579-9586.

27. Su YK, Eun YP, Kyounghee O, Keeho P (2015) Perceptions of Cancer Risk and Cause of Cancer Risk in Korean Adults. Cancer Research and Treatment 47(2): 158-165.

28. Elisa TL, Oscar TG (1997) Survival Analysis in Public Health Research. Annual review of public health 18(1): 105-134.

29. Soraya M, Ahmad RB, Mohamad AP, Ali AKM, Soodeh S, et al. (2017) Application of the Parametric Regression Model with the Fourparameter Log-Logistic Distribution for Determining of the Eecting Factors on the Survival Rate of Colorectal Cancer Patients in the Presence of Competing Risks. Iranian Red Crescent Medical Journal 19(6).
30. Robert J Gray (1988) A class of K-Sample Tests for Comparing the Cumulative Incidence of a Competing Risk. The Annals of statistics pp: 1141-1154.

31. Pegah M, Parvin Y, Mohammad EA, Alireza A, Farzane A (2014) The Correlation between the Family Levels of Socioeconomic Status and Stage at Diagnosis of Breast Cancer. Iranian journal of cancer prevention 7(4): 232238.

32. Ramakrishnan M, Ravanan R (2013) Non-Parametric Methods for Comparing Two Survival Distributions. Researchers World 4(2): 1-5.

33. Abbas R, Janet P, Daniel R, Abdolrasoul T, Seyed VH, et al. (2009) Survival Analysis of 1148 Women Diagnosed with Breast Cancer in Southern Iran. BMC cancer 9(1): 168.

34. German R (2010) Parametric survival models. Technical report, Technical report, pp: 1-14.

35. David S (1982) Partial residuals for the proportional hazards regression model. Biometrika 69(1): 239-241.

36. Shigeta K, Baba H, Yamafuji K, Asami A, Takeshima K, et al. (2016) Eects of laparoscopic surgery on the patterns of death in elderly colorectal cancer patients: competing risk analysis compared with open surgery. Surgery today 46(4): 422-429.

37. Maryam S, Mueen DA, Muhammad KP, Muhammad G, Gulzar HS, et al. (2012) Survival analysis of dialysis patients under parametric and non- parametric approaches. Electronic Journal of Applied Statistical Analysis 5(2): 271-288.

38. Terry M, Patricia M, Grambsch (2013) Modeling survival data: extending the Cox model. Springer Science \& Business Media.

39. Thruseld M (2013) Veterinary Epidemiology, Elsevier.

40. Lee JW (1992) The accelerated failure time model: a useful alternative to the cox regression model in survival analysis. Statistics in medicine 11(14-15): 1871-1879.

41. Fernando AW, Yang W, Jim PS (2014) The role of sick leave in increasing breast cancer screening among female employees in the us. Journal of Cancer Policy 2(3): 89-92.

42. Hui PZ, Xin X, H YC, Ahmed A, Shun FL, et al. (2011) Application of Weibull Model for Survival of Patients with Gastric Cancer. BMC gastroenterology 11(1): 1-6.

43. Abedi S, Moosazadeh M, Afshari M, Charati JY, 
Nezammahalleh A (2017) Determinant factors for mortality during treatment among tuberculosis patients: Cox proportional hazards model. Indian Journal of Tuberculosis 66(1): 39-43.

44. Alireza A, Parvin Y, Monireh DA, Hamid AM, Erfan G (2014) Cox Models Survival Analysis Based on Breast Cancer Treatments. Iranian journal of cancer prevention 7(3): 124-129.
45. Nadjib B, Arman, Kasim MA, Fatmah AG, Syamsidar (2018) Cox Proportional Hazard Survival Analysis to Inpatient Breast Cancer Cases. Journal of Physics: Conference Series, pp: 2-9.

46. Siavosh A, Mahmood M, Mahdi A, Jamshid YC, Asghar $N$ (2019) Determinant factors for mortality during treatment among tuberculosis patients: Cox proportional hazards model. Indian Journal of Tuberculosis 66(1): 3943. 